\title{
Impact of live trapping on the stress response of the meadow vole (Microtus pennsylvanicus)
}

\author{
Q. E. Fletcher \& R. Boonstra \\ Department of Life Sciences, Centre for the Neurobiology of Stress, University of Toronto at Scarborough, Scarborough, ONT, Canada
}

\author{
Keywords \\ glucocorticoids; live-trapping stress; \\ hypothalamic-pituitary-adrenocortical axis; \\ small mammals.

\section{Correspondence} \\ Rudy Boonstra, Department of Life \\ Sciences, Centre for the Neurobiology of \\ Stress, University of Toronto at \\ Scarborough, 1265 Military Trail, \\ Scarborough, ONT, Canada M1C 1 A4 \\ Tel: 1-416-287-7442; Fax: 1-416-287-7642 \\ Email: boonstra@utsc.utoronto.ca \\ Received 20 July 2005; accepted \\ 23 February 2006 \\ doi:10.1111/j.1469-7998.2006.00153.x
}

\begin{abstract}
In physiological research on natural populations, it is essential to understand the impact of capture-induced stress because of its numerous effects on many physiological processes. Our objective was to determine the extent to which the stress levels of meadow voles Microtus pennsylvanicus were affected by short-term responses to live trapping and how these were influenced by the amount of time spent in live traps. Baseline levels were obtained from a snap-trapped sample and stress levels were determined from voles that had spent variable amounts of time in live traps (up to $16.5 \mathrm{~h}$ ). Stress levels were inferred from corticosterone and glucose concentrations and haematocrit levels. In the live-trapped sample, corticosterone concentrations reflect only the stress of trap confinement whereas glucose concentrations and haematocrit reflect both the effects of trap confinement and handling. Live trapping caused corticosterone concentrations to increase by $108 \%$ (from 390.3 to $810.6 \mathrm{ng} \mathrm{mL}^{-1}$ ), glucose concentrations to increase by $58 \%$ (from 55.4 to $87.4 \mathrm{mg} \mathrm{dL}^{-1}$ ) and haematocrit levels to increase by $10 \%$ (from 49 to $54 \%$ ) from baseline levels. The length of time a vole spent in a live trap did not affect corticosterone and glucose concentrations; however, haematocrit levels increased slightly over time $\left(0.21 \% \mathrm{~h}^{-1}\right)$. We conclude that live trapping induced a stress response in voles, but that longer times in traps did not increase the stress levels.
\end{abstract}

\section{Introduction}

Activation of the stress response following exposure to real (e.g. predator attack) and perceived threats (e.g. the fear of an attack) affects most physiological systems (Eilam et al., 1999; Sapolsky, Romero \& Munck, 2000; Sapolsky, 2002). Within seconds of a stressor, catecholamines are released from the adrenal medulla via the sympathetic nervous system and within minutes glucocorticoids are released from the adrenal cortex via the hypothalamic-pituitary-adrenocortical (HPA) axis (Sapolsky et al., 2000). These hormones inhibit energy storage, stimulate energy mobilization and facilitate the delivery of energy to exercising muscles by elevating breathing rate, heart rate and blood pressure. The glucocorticoids also have numerous neurobiological and immunological effects, acting to inhibit digestion, inflammation and reproduction during a stress response (Sapolsky et al., 2000). The functioning of the stress axis is pivotal for successful adaptations that permit animals to maximize their fitness. It plays a central role in diurnal and seasonal changes in activity (e.g. Dallman et al., 1987; Romero, 2002), in responses to acute environmental challenges (e.g. Wingfield \& Hunt, 2002) and in long-term evolutionary adaptations to particular habitat pressures (e.g. Boonstra, 2005). It also plays a key role when animals are chronically stressed, as there are major negative effects on population demography (Boonstra et al., 1998; Hik, McColl \& Boonstra,
2001; Clinchy et al., 2004). Thus, understanding how it functions gives us critical insights into the ecology of organisms.

Live trapping is an essential methodology in the study of ecology of many animals in their natural environment, particularly those that are under a few thousand grams in mass. However, it is clearly stressful, causing a rapid activation of the HPA axis (e.g. Ortiz \& Worthy, 2000; Boonstra, McColl \& Karels, 2001; Reeder et al., 2004). Within 3 min of the initiation of a stress response, a surge of glucocorticoids is released into general circulation (Seggie \& Brown, 1975; Redei et al., 1994). Thus, the very process we are interested in studying may be biased by the technique used to acquire the samples. One approach is to assess directly the impact of live trapping on the stress response. Kenagy \& Place (2000) and Place \& Kenagy (2000) compared the levels of glucocorticoids of yellow-pine chipmunks Tamias amoenus as soon as they entered the traps (thus these were baseline levels) with those obtained on these same animals $30 \mathrm{~min}$ later. They found that the $30 \mathrm{~min}$ samples accurately depicted the seasonal changes in glucocorticoids. A second approach is to recognize that the bias occurs and to treat it as a constant by standardizing collection procedures and times and examining the differences that occur among animals independent of the bias. A third is to use a hormonal-challenge protocol that overrides the immediate effects of capture and handling to get an insight into stress axis responsiveness (e.g. Boonstra et al., 1998). 
A key confounding factor that may increase variation among animals may be the differential lengths of time animals spend in a live trap. Harper \& Austad (2001) found a positive relationship between length of time in the trap and faecal glucocorticoid levels in deermice Peromyscus maniculatus, but no such relationship (using both faecal glucocorticoids and plasma corticosterone) in red-backed voles Clethrionomys gapperi. However, these findings may be compromised, as the faecal corticosterone assay was not sensitive to the majority of corticosterone metabolites (Touma et al., 2003) nor were the animals sampled at the same time of day. The glucocorticoid circadian rhythm (Seabloom, 1985; Dallman et al., 1987) and diurnal fluctuations of glucocorticoid passage rate through the digestive system into the faeces may have influenced the results (Touma et al., 2003; Touma, Palme \& Sachser, 2004). Thus, it is critical to know whether length of time in the live trap affects glucocorticoid levels and to standardize when samples are collected.

We have two objectives in this study, both of which are needed to interpret ecophysiological research: (1) to determine the impact of live trapping on stress levels in meadow voles and (2) to determine how the length of time in a live trap affects stress levels. We used changes in corticosterone concentrations, glucose concentrations and packed redblood cell volume (haematocrit) as measures of the stress response. Corticosterone is the dominant glucocorticoid in voles (McDonald \& Taitt, 1982), glucose is mobilized in response to stressors (Sapolsky et al., 2000), and haematocrit increases in response to a stressor because a stressrelated surge of catecholamines causes the spleen to contract, releasing red blood cells into general circulation (Guntheroth \& Mullins, 1963; Opdyke, 1970).

\section{Methods and materials}

\section{Live trapping}

Research was conducted at the University of Toronto's Koffler Scientific Reserve at Jokers Hill, Regional Municipality of York, Ontario, Canada $\left(44^{\circ} 03^{\prime} \mathrm{N}, 79^{\circ} 29^{\prime} \mathrm{W}\right)$ between 13 September and 10 November 2003. We live trapped two checkerboard grids. The Willow Ridge grid (56 trap points) was an $8 \times 7$ grid dominated by Solidago altissima, Bromus inermis and Poa pratensis. The Racing Barn grid (91 trap points) was an irregular-shaped grid dominated by Phalaris arundinacea. One Longworth live trap was placed at each trapping station and the inter-trap interval was $7.5 \mathrm{~m}$. A small piece of plywood covered each trap, providing protection from the elements. Traps were prebaited with oats for more than 1 month before trapping. Oats were added to the live traps on two occasions during the prebait period.

The Willow Ridge and Racing Barn grids were trapped on the nights of 29 October and 31 October, respectively. The two grids were separated by $>1 \mathrm{~km}$ of open fields and forested habitat; therefore, it is unlikely that we captured the same individual on both grids. Our trapping protocol allowed us to determine the range of time over which a vole was captured during the night. In the afternoon, the traps were baited with oats, provided with cotton for warmth, and locked closed to minimize the amount of time that it would take to set the traps. At 16:30 h, approximately two-thirds of the traps on the grid were set. At 20:15 h, we recorded whether a vole had been captured in each trap by examining the trap doors with a flashlight. The traps were checked again at 00:00 $\mathrm{h}$ and the remaining one-third of the traps were set at this time. All the traps were checked again at 03:45 and 07:30 h. We set more than half the traps at 16:30 h in anticipation that not all the traps would be filled before 00:00 h. As a result, we expected to have an approximately equal number of traps set at 16:30 and 00:00 h. We minimized disturbance to the captured voles throughout the night by not approaching traps that we knew had already captured voles. Captured voles were bled starting at 09:00 h. The interval between checks was $3.75 \mathrm{~h}$, except between 07:30 and 09:00 $\mathrm{h}$ when it was only $1.5 \mathrm{~h}$. Using this protocol, each individual that was captured was approached once while it was in a trap, except for those individuals that were captured between 07:30 and 09:00 h. As a result, there were five possible intervals that the voles could be captured in: (1) $16: 30-20: 15 \mathrm{~h}$, (2) $20: 15-00: 00 \mathrm{~h}$, (3) $00: 00-03: 45 \mathrm{~h}$, (4) $03: 45-07: 30 \mathrm{~h}$ and (5) 07:30-09:00 h.

Starting at 09:00h, the captured voles were bled and processed. Each trap that contained a vole was approached and the contents of the trap were immediately emptied into a bucket. A $75 \mu \mathrm{L}$ blood sample was obtained from the retroorbital sinus using a heparinized microhaematocrit tube (Fisher Scientific, Pittsburgh, PA, USA). Bradshaw (2003) has suggested that this bleeding method is the most efficient and least stressful means of collecting small blood samples. All samples were obtained within 1.5 min of picking up the trap, well before the stress-related surge of corticosterone is released into general circulation. To minimize the effects of the circadian rhythm of stress hormones, all blood samples were collected over a $3 \mathrm{~h}$ period (09:00-12:00 h). For each vole, we recorded mass, sex and reproductive condition (males - testes abdominal or scrotal; females - vagina perforated or imperforated and nipples lactating or not). We recorded the same information for the snap-trapped voles (see below).

\section{Snap trapping}

Voles were snap trapped at least $100 \mathrm{~m}$ away from the livetrapping grids. Snap trapping occurred on the day when the Racing Barn grid was live trapped and on 4 additional days up to and including 10 November. We modified Museum Special snap traps (Woodstream Corp., Lititz, PA, USA) so that we could see when a vole had been killed. The bottom of a metal flag (Canadian Forestry Equipment, Edmonton, $\mathrm{AB}$, Canada) was bent so that it slid onto the wood base of the snap trap. When a vole triggered the treadle, the snapping mechanism simultaneously killed the vole and knocked over the flag. Immediately after a flag was knocked over, we collected a $100 \mu \mathrm{L}$ blood sample from the inferior vena cava using a heparinized syringe (Bectin Dickson, 
Franklin Lakes, NJ, USA; $0.5 \mathrm{~cm}^{3}, 28 \mathrm{Ga}$ needle). All voles were snap trapped between 07:30 and 11:30 h. The interval between when an animal was snap trapped and the blood sample was collected was less than 2 min for all individuals. The University of Toronto animal care committee approved all procedures in accordance with the guidelines of the Canadian Council on Animal Care.

\section{Stress levels}

A glucose reading was determined immediately using $0.3 \mu \mathrm{L}$ of blood (TheraSense Inc., Alameda, CA, USA). The blood samples were kept on ice and were centrifuged for $4 \mathrm{~min}$ $(4750 \times g$; Eppendorf; Hamburg, Germany). Levels of haematocrit were measured as percentage packed red blood cell volume using a microhaematocrit capillary tube reader (Oxford Labware, St Louis, MO, USA). To control for between-observer variability, one person obtained all glucose and haematocrit readings. The separated plasma was then stored at $-70{ }^{\circ} \mathrm{C}$ until analysis for corticosterone. Plasma corticosterone was measured by radioimmunoassay using the methods in Boonstra \& Boag (1992). The intraand inter-assay coefficients of variation for the corticosterone assay were 10 and $16 \%$, respectively.

\section{Statistical analysis}

All statistical analyses were performed using Statistica (StatSoft Inc., 2001). We used a two-way analysis of variance (ANOVA) to test for differences in response to (1) the amount of time a vole spent in a trap [0 h (i.e. snap trapped), less than $9 \mathrm{~h}$ and greater than $9 \mathrm{~h}]$, (2) sex, and (3) the interaction between the two. Post hoc comparisons among means were performed using Tukey's multiple comparison test. Analysis of covariance (ANCOVA) was also used to examine the relationship between the amount of time the voles spent in the live traps and their levels of stress. The null hypothesis was rejected at $P<0.05$. Glucose and total corticosterone data were $\log (x+1)$ transformed and haematocrit data were $\operatorname{arcsine}\left(x^{1 / 2}\right)$ transformed to meet the homogeneity of variance assumption. When reporting percentage changes and means in the text, we used back transformed means $\pm 95 \%$ confidence intervals.

\section{Results}

Seventy-seven voles (48 males, 56 females) were live trapped during the following intervals: (1) 16:30-20:15 h $(n=39$; 15 males, 24 females), (2) 20:15-00:00 h ( $n=4$; two males, two females), (3) 00:00-03:45 h ( $n=24 ; 15$ males, nine females), (4) $03: 45-07: 30 \mathrm{~h}(n=8$; six males, two females) and (5) 07:30-09:00 h ( $n=2$; one male, one female). Because only 4 , 8 , and $2 \%$ of the voles were live trapped in the second, fourth and fifth intervals, respectively, the individuals captured in the first and second intervals were pooled to form a group that had been in the live traps for greater than $9 \mathrm{~h}(9-16.5 \mathrm{~h})$. The individuals captured in intervals three, four and five were also pooled, constituting a group that had been in the live traps for less than $9 \mathrm{~h}$. In addition to the live-trapped voles, 27 (nine males, 18 females) voles were snap trapped.
The two-way ANOVA on corticosterone levels (sex $\times$ time) indicated a significant sex effect $\left(F_{1,98}=5.3, P<0.02\right)$, a significant time effect $\left(F_{2,98}=22.1, P<0.0001\right)$ and no interaction effect $\left(F_{2,98}=0.5, P=0.61\right)$. Corticosterone levels were greater in females than in males [females $=713.3 \mathrm{ng} \mathrm{mL}^{-1} \quad\left(596.6-852.8 \mathrm{ng} \mathrm{mL}^{-1}\right), \quad$ males $\left.=623.8 \mathrm{ng} \mathrm{mL}^{-1}\left(539-721 \mathrm{ng} \mathrm{mL}^{-1}\right)\right]$; presumably this can be attributed to the effects of the sex-specific reproductive hormones on the HPA axis (Viau \& Meaney, 1991; Handa et al., 1994). There was no difference between the voles that were in live traps for less than or greater than $9 \mathrm{~h}$ (post hoc $P=0.72$ ), but live-trapped voles had higher corticosterone levels than those in snap-trapped voles (post hoc $P<0.001$; Fig. 1a). Levels in the live-trapped voles were $108 \%$ greater than those in the snap-trapped voles [all live-trapped voles pooled $=810.6 \mathrm{ng} \mathrm{mL}^{-1}\left(727.6-903.1 \mathrm{ng} \mathrm{mL}^{-1}\right)$, snaptrapped voles $\left.=390.3 \mathrm{ng} \mathrm{mL}^{-1}\left(309.7-491.8 \mathrm{ng} \mathrm{mL}^{-1}\right)\right]$.

The two-way ANOVA on glucose levels (sex $\times$ time) indicated no sex effect $\left[F_{1,98}=0.6, \quad P>0.45 ;\right.$ males $=78.8 \mathrm{mg} \mathrm{dL}^{-1} \quad\left(70.9-87.6 \mathrm{mg} \mathrm{dL}^{-1}\right), \quad$ females $=76.8 \mathrm{mg}$ $\left.\mathrm{dL}^{-1} \quad\left(69.9-84.2 \mathrm{mg} \mathrm{dL}^{-1}\right)\right]$, a significant time effect $\left(F_{2,98}=22.3, P<0.0001\right)$ and no interaction effect $\left(F_{2,98}\right.$ $=0.3, P=0.75)$. There was no difference between the voles that were in live traps for less than or greater than $9 \mathrm{~h}$ (post hoc $P=0.81$ ), but live-trapped voles had higher glucose levels than those in snap-trapped voles (post hoc $P<0.001$; Fig. 1b). Levels in the live-trapped voles were $58 \%$ greater than those in the snap-trapped voles [all live-trapped voles pooled $=87.4 \mathrm{mg} \mathrm{dL}^{-1}\left(88.3-91.8 \mathrm{mg} \mathrm{dL}^{-1}\right)$, snap-trapped voles $\left.=55.4 \mathrm{mg} \mathrm{dL}^{-1}\left(46.4-66.3 \mathrm{mg} \mathrm{dL}^{-1}\right)\right]$.

Because we pooled the data from the live-trapped individuals into two groups, the resolution of our comparison may have been too coarse to detect a threshold effect of less than $9 \mathrm{~h}$ (i.e. levels increased rapidly and then stabilized). We think this is unlikely. The mean levels of corticosterone and glucose for the individuals that had been in traps for up to 1.5 and $5.25 \mathrm{~h}$ were greater than levels in the snap-trapped voles (Fig. 1a, b; $t$-tests comparing the snap-trapped voles with those that were in live traps for up to 1.5 and $5.25 \mathrm{~h}$ : corticosterone: $t_{35}=4.1, \quad P=0.0002$; glucose: $t_{35}=4.6$, $P<0.0001)$. Moreover, when the relationship between the actual amount of time a vole spent in a live trap (i.e. values not pooled into less than and greater than $9 \mathrm{~h}$ groups) and levels of corticosterone and glucose is examined with ANCOVA, there is no relationship for either of these variables (corticosterone: $F_{1,74}=0.1, P=0.74$; glucose: $F_{1,74}=1.5$, $P=0.22$; note that the effect of sex on levels on corticosterone and glucose was the same as in the ANOVA analysis).

The two-way ANOVA on haematocrit levels (sex $\times$ time) indicated no sex effect $\left[F_{1,98}=0.9, \quad P=0.36 ;\right.$ male haematocrit $=53 \%(52-54 \%)$, female haematocrit $=54 \%$ $(52-55 \%)]$, a significant time effect $\left(F_{2,98}=19.8, P<0.0001\right)$ and no interaction effect $\left(F_{2,98}=0.3, P=0.74\right)$. There was no difference between the voles that were in live traps for less than or greater than $9 \mathrm{~h}$ (post hoc $P=0.12$ ); however, the live-trapped voles had higher haematocrit levels than those in snap-trapped voles (post hoc $P<0.001$; Fig. 1c). Levels in the live-trapped voles were $10 \%$ greater than those in the 
(a)
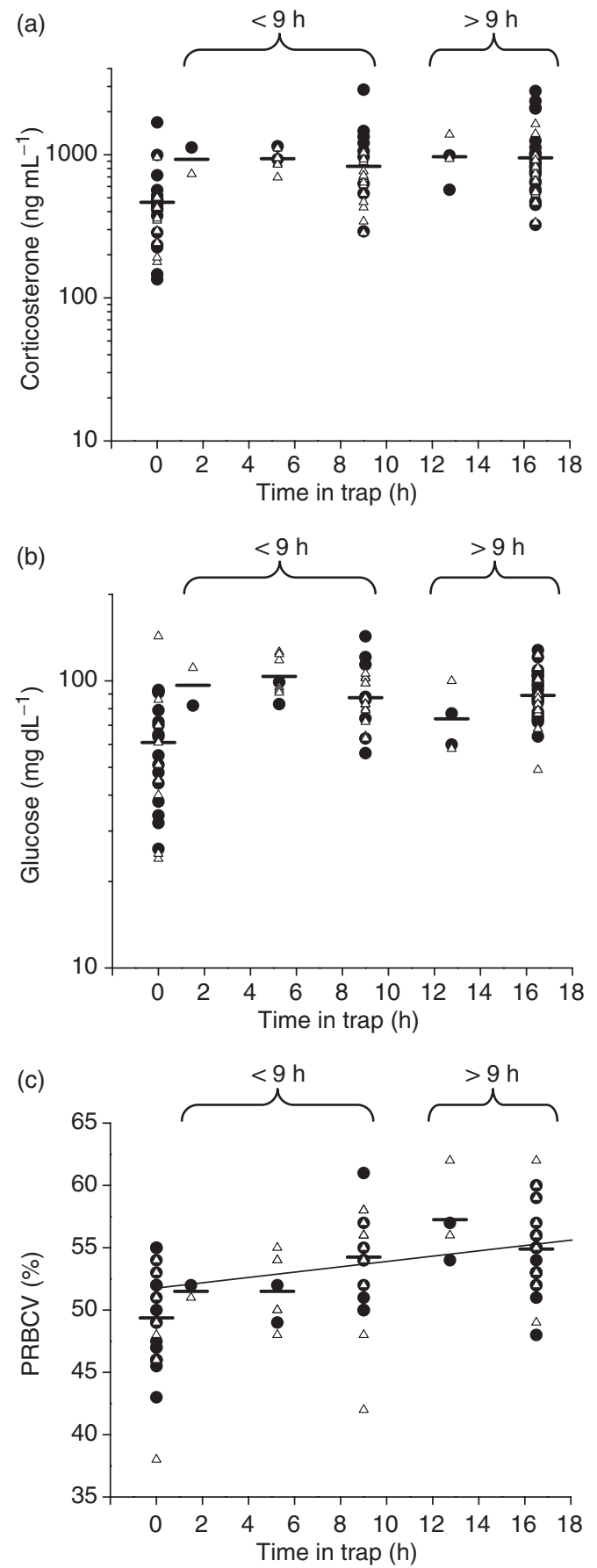

Figure 1 Response of meadow voles Microtus pennsylvanicus to capture stress: (a) corticosterone, (b) glucose and (c) haematocrit levels [packed red blood cell volume (PRBCV)] in voles after being snap trapped (zero hours) or in live traps for varying amounts of time. Levels of corticosterone and glucose are plotted on a $\log _{10}$ scale. The time in the trap indicates the maximum amount of hours a vole could have spent in a live trap ( $0 \mathrm{~h}$ for individuals that were snap trapped). Each point (female: filled circles; males: open triangles) represents a value from one vole and the horizontal lines are the means for the trapping intervals. The regression line for the haematocrit levels is fitted for only the live-trapped individuals. snap-trapped voles [all live-trapped voles pooled $=54 \%$ $(54-55 \%)$, snap-trapped $=49 \%(48-51 \%)]$. When haematocrit levels were examined using ANCOVA, a different picture emerges. When only the live-trapped individuals are analysed, there is a positive relationship between the actual amount of time a vole spent in a live trap (i.e. values not pooled into less than and greater than $9 \mathrm{~h}$ groups) and haematocrit levels $\left(F_{1,74}=7.1, P<0.001 ; y=0.21 x+51.8\right.$; $\left.r^{2}=0.07\right)$. It appears that the two-way ANOVA did not detect an effect of the amount of time spent in a trap because pooling the data obscured the effect.

Because reproductive hormones affect the stress response (Handa et al., 1994; Viau, 2002), we performed this study in the fall when the majority of voles were nonreproductive. However, $19 \%$ of the voles were in breeding condition, but we could not include the reproductive state of the voles as a factor in the ANOVA because the analysis would have been unbalanced. Nevertheless, the reproductive condition of the voles presumably did not change the interpretation of our results because only a few of the voles that we captured were reproductive $(2.8 \%$ of the males were scrotal, $5.7 \%$ of the females had perforated vaginas and $10.5 \%$ of the females were lactating) and there was no obvious bias with respect to when these individuals were captured [the proportion of scrotal males, perforated females or lactating females did not exceed 0.67 in any of the three classes (i.e. snap trapped, less than $9 \mathrm{~h}$ and greater than $9 \mathrm{~h}$ )]. Moreover, if the corticosterone, glucose and haematocrit analyses are performed without the reproductive individuals, the interpretation of the results does not change (analyses not shown).

\section{Discussion}

Live trapping clearly stressed the voles (all measures corticosterone, glucose and haematocrit - being greater in live-trapped than snap-trapped voles). However, there was no relationship between the amount of time spent in a live trap and corticosterone and glucose levels (Fig. 1a, b), although there was a small increase in haematocrit levels with time (Fig. 1c). The lack of a time effect is good news to researchers conducting ecophysiological research on the stress axis in natural populations of small mammals (assuming this relationship holds in other populations and in other species), as it means they do not have to worry about the length of time the animals have been in the trap. Thus they may be able to treat the impact of trapping on the stress axis as a constant bias.

The relative role of trap confinement versus handling was not the same for all measures of the stress response. Increases in corticosterone concentrations were not a result of handling effects, but rather of the stress of trap confinement. We were able to obtain a blood sample in under $1.5 \mathrm{~min}$, and it takes at least $3 \mathrm{~min}$ for the adrenal cortex to receive the adrenocorticotropic hormone (ACTH) signal from the pituitary and start releasing corticosterone into the general circulation (Seggie \& Brown, 1975; Redei et al., 1994). We hypothesize that the corticosterone concentrations increased as soon as the voles realized that they were confined in a trap and could not escape, similar to the effects of novelty on the 
levels of corticosterone in laboratory rats (Muir \& Pfister, 1987). In contrast, handling could have caused some of the increase in glucose and haematocrit as at least part of their increase is essentially instantaneous (i.e. because of nervous innervations; see the Introduction for references). Nevertheless, at least for glucose, these handling effects, if they occurred, produce a constant effect independent of how long the voles were confined in the live traps (Fig. 1b).

There are two additional factors that need to be considered with respect to live-trapping stress. First, all the animals we tested were naïve - that is they had never been captured before, although they would have had extensive experience with the traps as these had been left on site and locked open for about 1 month. Animals that have been captured repeatedly appear much more relaxed, often calmly sitting in the trapping bucket waiting to be processed and released, rather than running about frantically (R. Boonstra, pers. obs.). Thus, we expect that measures of the stress response of animals familiar with the trapping routine should be lower than observed here. Second, for the animals that have been stressed by trap confinement, the question remains as to whether they are only mildly stressed by this experience and have remaining capacity for responding to a subsequent stressor. Although the research presented here did not address this question, other research we have done using a restraint paradigm following trap confinement clearly indicates that they can still respond vigorously (R. Boonstra \& Q. E. Fletcher, pers. comm.). Thus, although trap confinement clearly stresses these small mammals, they have additional capacity to respond to other stressors.

The slope of the positive relationship between the amount of time a vole spent in a live trap and its haematocrit levels, although statistically significant, was not steep $\left(0.21 \% \mathrm{~h}^{-1}\right)$. Also, the small $r^{2}(7 \%)$ suggests marginal biological significance. Hence we conclude that length of time in the trap is unlikely to have had major effects on red blood cells over the initial increase in levels. One possible explanation for the positive relationship is that voles became mildly dehydrated while they spent extended periods of time in live traps. As a result, the volume of plasma decreased and the concentration of red blood cells in blood increased (Buffenstein, Maloney \& Bronner, 1999). In future studies in which animals may spend extended periods of time in live traps, a source of water (e.g. a piece of apple or carrot) should be provided to prevent dehydration.

Live-trapping stress has the potential of long-term demographic effects if pregnant or lactating females are captured. Laboratory research has indicated that the offspring of mothers that experience high levels of stress during pregnancy, or receive low levels of maternal care during their neonatal life are nongenetically programmed to have a dysfunctional stress axis, which can compromise survival and reproduction (Meaney, 2001; Matthews, 2002; Wartella et al., 2003). Evidence is accumulating to indicate that natural stressors have a negative effect on free-ranging animals in the same manner that they affect laboratory animals (Romero, 2004). Boonstra et al. (in press) have suggested that the reason why meadow voles and snowshoe hares Lepus americanus collected from the low phase of their population cycles breed poorly in captivity (Mihok \& Boonstra, 1992; Sinclair et al., 2003) may be related to the programming effects of the stress axis that result from high levels of predator stress during the population peak. Moreover, recent research indicates that attaching radio collars to female water voles Arvicola terrestris may cause sufficient stress to skew the sex ratio of the progeny (Moorhouse \& Macdonald, 2005). Additional research is needed to evaluate these possibilities.

In conclusion, our results indicate that meadow voles are stressed by being captured in live traps, but that an increased time of confinement does not result in progressively higher stress levels. Thus, one can treat the trapping effect as a constant bias and take this into consideration when asking meaningful ecophysiological questions on the role of the stress axis in the ecology of wild animals.

\section{Acknowledgements}

We thank M. Sanders for designing the modified snap traps and A. Zimmerman, J. Jensen and M. Johnson for showing us the Joker's Hill site. We thank K. Edwards and K. Magnusson for helpful comments that improved the manuscript. This work was funded by a Natural Sciences and Engineering Research Council (NSERC) operating grant awarded to R. B.

\section{References}

Boonstra, R. (2005). Equipped for life: the adaptive role of the stress axis in male mammals. J. Mammal. 86, 236-247.

Boonstra, R., Barker, J.M., Castillo, J.G.M. \& Fletcher, Q.E. (in press). The role of the stress axis in life-history adaptations of rodents. In Rodent societies: an ecological and evolutionary perspective. Wolff, J.O. \& Sherman, P.W. (Eds). Chicago: Chicago University Press.

Boonstra, R. \& Boag, P.T. (1992). Spring declines in Microtus pennsylvanicus and the role of steroid hormones. J. Anim. Ecol. 61, 339-352.

Boonstra, R., Hik, D., Singleton, G.R. \& Tinnikov, A. (1998). The impact of predator-induced stress on the snowshoe hare cycle. Ecol. Monogr. 68, 371-394.

Boonstra, R., McColl, C.J. \& Karels, T. (2001). Reproduction at all costs: the adaptive stress response of male arctic ground squirrels. Ecology 82, 1930-1946.

Bradshaw, D. (2003). Vertebrate ecophysiology - an introduction to its principles and applications. Cambridge: Cambridge University Press.

Buffenstein, R., Maloney, S.K. \& Bronner, G.N. (1999). Seasonal and daily variation in blood and urine concentrations of free-ranging Angolan free-tailed bats (Mops condylurus) in hot roosts. S. Afr. J. Zool. 34, 11-18.

Clinchy, M., Zanette, L., Boonstra, R., Wingfield, J.C. \& Smith, J.N.M. (2004). Balancing food and predator pressure induces chronic stress in songbirds. Proc. Roy. Soc. Lond. Ser. B 271, 2473-2479. 
Dallman, M.F., Akana, S.F., Cascio, C.S., Darlington, D.N., Jacobson, L. \& Levin, N. (1987). Regulation of ACTHsecretion - variations on a theme of B. Recent Prog. Horm. Res. 43, 113-173.

Eilam, D., Dayan, T., Ben-Eliyahu, S., Schulman, I., Shefer, G. \& Hendrie, C.A. (1999). Differential behavioural and hormonal responses of voles and spiny mice to owl calls. Anim. Behav. 58, 1085-1093.

Guntheroth, W.G. \& Mullins, G.L. (1963). Liver and spleen as venous reservoirs. Am. J. Physiol. 204, 35-41.

Handa, R.J., Burgess, L.H., Kerr, J.E. \& O'Keefe, J.A. (1994). Gonadal steroid hormone receptors and sex differences in the hypothalamo-pituitary-adrenal axis. Horm. Behav. 28, 464-476.

Harper, J.M. \& Austad, S.N. (2001). Effect of capture and season on fecal glucocorticoid levels in deer mice (Peromyscus maniculatus) and red-backed voles (Clethrionomys gapperi). Gen. Comp. Endocrinol. 123, 337-344.

Hik, D.S., McColl, C.J. \& Boonstra, R. (2001). Why are arctic ground squirrels more stressed in the boreal forest than in alpine meadows? Ecoscience 8, 275-288.

Kenagy, G.J. \& Place, N.J. (2000). Seasonal changes in plasma glucocorticosteroids of free-living female yellowpine chipmunks: effects of reproduction and capture and handling. Gen. Comp. Endocrinol. 117, 189-199.

Matthews, S.G. (2002). Early programming of the hypothalamopituitary-adrenal axis. Trends Endocrinol. Met. 13, 373-380.

McDonald, I.R. \& Taitt, M.J. (1982). Steroid hormones in the blood plasma of Townsend's vole (Microtus townsendii). Can. J. Zool. 60, 2264-2269.

Meaney, M.J. (2001). Maternal care, gene expression, and the transmission of individual differences in stress reactivity across generations. Annu. Rev. Neurosci. 24, 1161-1192.

Mihok, S. \& Boonstra, R. (1992). Breeding performance in captivity of meadow voles (Microtus pennsylvanicus) from decline-phase and increase-phase populations. Can. J. Zool. 70, 1561-1566.

Moorhouse, T.P. \& Macdonald, D.W. (2005). Indirect negative impacts of radio-collaring: sex ratio variation in water voles. J. Appl. Ecol. 42, 91-98.

Muir, J.L. \& Pfister, H.P. (1987). Time course of the corticosterone and prolactin response following predictable and unpredictable novelty stress in Rattus norvegicus. Physiol. Behav. 40, 103-107.

Opdyke, D.F. (1970). Hemodynamics of blood flow through the spleen. Am. J. Physiol. 219, 102-106.

Ortiz, R.M. \& Worthy, G.A.J. (2000). Effects of capture on adrenal steroid and vasopressin concentrations in freeranging bottlenose dolphins (Tursiops truncatus). Comp. Biochem. Phys. A 125, 317-324.

Place, N.J. \& Kenagy, G.J. (2000). Seasonal changes in plasma testosterone and glucocorticosteroids in free-living male yellow-pine chipmunks and the response to capture and handling. J. Comp. Physiol. B 170, 245-251.

Redei, E., Li, L.F., Halasz, I., McGivern, R.F. \& Aird, F. (1994). Fast glucocorticoid feedback inhibition of ACTH- secretion in the ovariectomized rat: effect of chronic estrogen and progesterone. Neuroendocrinology 60, 13-123.

Reeder, D.M., Kosteczko, N.S., Kunz, T.H. \& Widmaier, E.P. (2004). Changes in baseline and stress-induced glucocorticoid levels during the active period in free-ranging male and female little brown myotis, Myotis lucifugus (Chiroptera: Vespertilionidae). Gen. Comp. Endocrinol. 135, 260-269.

Romero, L.M. (2002). Seasonal changes in plasma glucocorticoid concentrations in free-living vertebrates. Gen. Comp. Endocrinol. 128, 1-24.

Romero, L.M. (2004). Physiological stress in ecology: lessons from biomedical research. Trends Ecol. Evol. 19, 249-255.

Sapolsky, R.M. (2002). Neuroendocrinology of the stressresponse. In Behaviorial endocrinology. 2nd edn: 409-450. Becker, J.B., Breedlove, S.M., Crews, D. \& McCarthy, M.M. (Eds). Cambridge, MA: MIT Press.

Sapolsky, R.M., Romero, L.M. \& Munck, A.U. (2000). How do glucocorticoids influence stress responses? Integrating permissive, suppressive, stimulatory, and preparative actions. Endocr. Rev. 21, 55-89.

Seabloom, R.W. (1985). Endocrinology. In Biology of New World Microtus: 685-724. Tamarin, R.H. (Ed.). Boston, MA: The American Society of Mammalogists.

Seggie, J.A. \& Brown, G.M. (1975). Stress response patterns of plasma corticosterone, prolactin, and growth-hormone in rat, following handling or exposure to novel environment. Can. J. Physiol. Pharm. 53, 629-637.

Sinclair, A.R.E., Chitty, D., Stefan, C.I. \& Krebs, C.J. (2003). Mammal population cycles: evidence for intrinsic differences during snowshoe hare cycles. Can. J. Zool. 81, 216-220.

StatSoft, Inc. (2001). Statistica for Windows. Tulsa, OK: StatSoft, Inc.

Touma, C., Palme, R. \& Sachser, N. (2004). Analyzing corticosterone metabolites in fecal samples of mice: a noninvasive technique to monitor stress hormones. Horm. Behav. 45, 10-22.

Touma, C., Sachser, N., Möstl, E. \& Palme, R. (2003). Effects of sex and time of day on metabolism and excretion of corticosterone in urine and feces of mice. Gen. Comp. Endocrinol. 130, 267-278.

Viau, V. (2002). Functional cross-talk between the hypothalamic-pituitary-gonadal and-adrenal axes. J. Neuroendocrinol. 14, 506-513.

Viau, V. \& Meaney, M.J. (1991). Variations in the hypothalamic-pituitary-adrenal response to stress during the estrous cycle in the rat. Endocrinology 129, 2503-2511.

Wartella, J., Amory, E., Macbeth, A., McNamara, I., Stevens, L., Lambert, K.G. \& Kinsley, C.H. (2003). Single or multiple reproductive experiences attenuate neurobehavioral stress and fear responses in the female rat. Physiol. Behav. 79, 373-381.

Wingfield, J.C. \& Hunt, K.E. (2002). Arctic spring: hormone-behavior interactions in a severe environment. Comp. Biochem. Physiol. B 132, 275-286. 